\title{
CRITICA ET BIBLIOGRAPHIA
}

WOLDAN Alois: Beiträge zu einer Galizienliteratur. (Wechselwirkungen. Österreichische Literatur im internationalen Kontext 16.) Frankfurt am Main: Peter Lang, 2015. $434 \mathrm{~S}$.

Jener Raum, den der Professor des Slawistischen Instituts der Wiener Universität, A. Woldan, aus unterschiedlichen Standpunkten untersucht, kann nicht nur im Rahmen der enger genommenen Slawistik in Evidenz gehalten werden, sondern soll auch von den im weiteren Sinne verstandenen Vertretern der vergleichenden Literaturwissenschaft mit Interesse verfolgt werden. Forscher der Literatur, Landeskunde, Ethnographie, Geschichte sowie der Berührungspunkte verschiedener Sprachen, Kulturen sind aus diesem Grund beinahe gezwungen, nicht anhand der bewährten Methoden der traditionellen, geschlossenen Disziplinen vorzugehen, sondern die von dem cultural turn mit Nachdruck gedrängten neueren „Verfahren“ durchzusetzen, beziehungsweise auf Bachtins Dialogizität umschreibende Thesen zurückzugreifen, und somit die Intertextualität, die postkoloniale Theorie, die semiotische „Schule“ von Tartu zweckmäßiger anzunähern, um die sprachliche, literarische und kulturelle Vielfalt dieser Region anhand dieser Vorschläge zu analysieren.

Der Titel des Studienbandes definiert sehr bescheiden die Zielsetzung: Der Band hat vor, Erläuterungen zur so genannten Galizienliteratur zu geben. Damit grenzt sich der Band von der Hypothese der Nationalliteratur ab, denn die Literaturen der ehemaligen Kronländer der Habsburgermonarchie werden nicht nebeneinander liegend, voneinander getrennt, einander gegenübergestellt untersucht, sondern in Wechselwirkung miteinander in ihrer Parallelität gezeigt. Die Darlegung der Literaturgeschichte Galiziens wird hier ebenfalls nicht als Ziel angesehen. Dies wäre schon aus dem Grunde nicht möglich, da die auf Deutsch und Polnisch verfassten Studien zu ganz unterschiedlichen Gegebenheiten publiziert wurden. Gleichzeitig ermöglicht - auf paradoxe Weise - gerade diese Heterogenität, dass die Literaturgeschichte Galiziens, gelegentlich nur die Haupttendenzen ihres Schrifttums, nicht stilgeschichtlich aufgefasst, sondern vielmehr als ideengeschichtliche Tendenzen angedeutet werden. Der fast alle Studien durchdringende Gedanke wird hier in erster Linie als Frage gestellt: Wie haben sich die polnischen, die ukrainischen (die russinischen), die jüdischen, die deutschsprachigen (österreichischen) literarischen Äußerungen einander gekreuzt; wie hat sich unter den verschiedenen Sprachen sprechenden (doch lange Zeit in einem mehrsprachigen Raum lebenden) Personen das gemeinsame galizische Bewusstsein herausgebildet (und wie hat es sich genau in jenem bestimmten Zeitalter herausgebildet) und wie zerfiel dieses Bewusstsein später; wie kann Galizien als Region beschrieben werden, die über sprachlich unterschiedliche Volksdichtungen verfügt; wie können die unterschiedlichen Schriftlichkeiten miteinander verglichen werden, die zwar miteinander verbunden sind, sich berühren, mal die Terminologien voneinander übernehmen, auch wenn die ab und zu bestrittene Identität von anderen ost- und mitteleuropäischen Identitäten abweichend war. Aus einer anderen Perspektive kann auch die folgende Frage gestellt werden: Wie können die erwähnten Literaturen mit den Literaturen des Habsburgerreiches oder mit dem 
zaristischen Russland verglichen werden? Können die Sprachverwandtschaft aufweisenden oder andere Literaturen der Formierung des regionalen und/oder nationalen Bewusstseins helfen oder sie gar hemmen? Im Zusammenhang damit kann festgestellt werden, dass (zum Beispiel) bei dem lange Zeit als Zentrum anerkannten Lemberg (Lvov, L'viv) im Falle der polnischen, ukrainischen und jüdischen Erinnerung die gemeinsame Vergangenheit völlig anders aufgefasst wird (wenn es überhaupt als Erinnerung noch lebt). Die Orte, Plätze der Erinnerung werden in einer ganz anderen Art und Weise gekennzeichnet, mit Hilfe ihrer Geschichtsschreibung wird die gemeinsame Geschichte ganz anders (re)konstruiert.

Oft kommen solche identitätsbildenden Kräfte als Vorwand formulierte Antwort auf die Frage der Modernität, die ansonsten in einem ästhetisch weniger erfolgreichen Roman die Darbietung der Volksstereotypie begünstigen. Die ukrainischen und polnischen Romane über Boryslavs Ölfundorte und die darauf angesiedelte Industrie bauen auf die Kontroverse zwischen dem Heimischen und dem Fremden und verhindern somit eine differenziertere Erzählweise, während das im Roman dargebotene und verarbeitete Tatsachenmaterial doch einige dokumentierte Vorzüge zum Ausdruck bringen kann.

Der Band beschäftigt sich in den meisten Fällen mit der Stadt Lemberg, die ein abwechslungsreiches Schicksal hat. Es wird zum Ausdruck gebracht, wie die Stadt in den ukrainischen und polnischen Geistesgeschichten in Erinnerung gebracht wird, und wie sie versucht hat, für sich die ukrainische und polnische Erinnerungspolitik zu enteignen, sowie wie die Stadt in dem Ersten Weltkrieg zu einer Frontstadt und zum neuen Symbol der antemurale christianitatis wurde. Eine Studie befasst sich damit, wie Krakau und Lemberg in das Heim der Mythen einzog. Ich kann noch hinzufügen, dass die Erinnerung an die Monarchievergangenheit das Leben in der Stadt in der abwechslungsreichen Geschichte oft verschönerte und neben den nostalgischen Gefühlen als Verwahrer, Behüter der europäischen geistigen und materiellen Kultur in die Erinnerungen und Romane brachte, sodass die Stadt nicht zuletzt als Erfüllung in die fruchtbringende Mehrsprachigkeit und Multikulturalität eingetragen wurde. Die Baudenkmäler, der Stadtbau, die Kaffeehauskultur Lembergs spielen darin eine genauso wichtige Rolle, wie ihre natürliche Mehrsprachigkeit; so zeigte sie zum Beispiel für die österreichische (und polnische) künstlerische Moderne große Offenheit.

Die zu entdeckenden Studien des Bandes werden von solchen Verfassern geschrieben und befassen sich mit Volkskulturen, die die einstige kulturelle Vielfarbigkeit hervorrufen. Der Verfasser des Bandes sieht diesmal davon ab, die Studien der aus Galizien stammenden und zu den eminenten Personen der Habsburger-Literatur gehörenden J. Roth oder E. Franzos auszuwählen. Auf der anderen Seite werden die Dichtungen des zur „kleinen Literatur" gehörenden Lemken bzw. in der polnischen Literatur wird die Lyrik der weniger namhaften Jerzy Harasymowicz (des Weiteren die Lyrik des ukrainischen Kontextes, die Dichtung des Bohdan Ihor Antonyč) aus der Vergessenheit herausgehoben. Es wird über den „Erinnerungsmonolog“ des einst sehr populären, heute jedoch etwas weniger bekannten Andrzej Kuśniewicz und über das Buch Mieszaniny obyczajowe berichtet.

Die Werke des aus Galizien stammenden deutsch-jüdischen Schriftstellers Hermann J. Blumenthal (1880-1942) werden mit Werken ähnlicher Thematik von polnischen und ukrainischen Dichtern konfrontiert. Wir erhalten gut dargestellte dichterische Porträts, doch die Studien begnügen sich nicht bloß mit der Darstellung der Werke als sprachliche Kunstwerke. Sie berichten über jene Rollen, die sie in der Konstruierung des Regionsbewusstseins spielen. Es handelt sich um Schöpfer, die neben der Tatsache, dass sie sich zu den Nationalliteraturen verpflichtet haben, in ihrer eigenen oder in mehreren Sprachen geschrieben haben (I. Franko). So schufen sie gemäß den Konventionen mehrerer Nationalliteraturen oder Diskussionstexte und somit wurden sie mit anderen Narrativen konfrontiert. 
Obwohl die einzelnen Figuren, Geschichten der Volksliteratur die Denkweise, die Redensart, die Lebensauffassung einer Volksgruppe, einer Minderheit besser, straffer veranschaulicht haben, waren in der literarischen Präsentierung der kleineren galizischen Minderheiten nicht nur die Stoff- und Motivgeschichte von transnationaler Bedeutung, sondern auch die auto- und heteroimagologischen Momente verfügten über wichtige Elemente.

Die Bearbeitung der Huzuler Betyargeschichten, die über die Huzuler verfassten mitteleuropäischen Erzählungen, die Huzul-Texte als Übergang von Sprachen, Gattungen und Zeitalter beweisen einerseits die Vielfältigkeit der Galizien-Literatur (von der archaischen bis zur modernen Literatur), andererseits beweisen sie die Zusammengesetztheit der Bestandteile der literarisch-kulturellen Region und sowie die Tatsache, dass die einzelnen Texte auf einer nationaler Ebene nicht einseitig enteignet werden können. Obwohl im Hintergrund (und oft sogar im Vordergrund) auch der österreichische Faktor vergegenwärtigt wird, bekommen wir über die oft missverstandenen und oft mit Absicht missgedeuteten Widersprüche von Zentrum und Peripherie gerade von den postkolonialen Theorien eine klare Erklärung.

Die „Hybridität“ des Galizien-Textes ermöglicht die Gültigmachung der ,,großen Erzählungen“" nicht. Jedoch haben sowohl die polnische als auch die ukrainische Literatur solche Repräsentanten (A. Stasziuk, J. Andruchovič), die nicht nur die gemeinsame Vergangenheit vor unsere Augen führen und neu denken wollen, sondern auch antreiben, die gemeinsame Gegenwart und die gemeinsame Zukunft zu planen. Eine von A. Woldans schönsten Abhandlungen würdigt diese Art der Tätigkeiten der beiden Verfasser. Aus diesem Grunde ist es sicherlich kein Irrtum, den Wiener Slawisten-Professor auch neben seine verehrten Schriftsteller zu setzen.

István Fried

\section{JAKOBSON Roman: Moudrost starých Čechů. Komentovaná edice s navazující} exilovou polemikou. K vydání připravili a studií doprovodili Tomáš Hermann a Miloš Zelenka. Praha: Červený Kostelec, 2015. 382 s.

W dziejach literatury stosunkowo rzadko spotykać można teksty ważne, które jednak z różnych powodów nie są dostępne szerokiemu kręgowi odbiorców, ale jednocześnie stanowią istotną część dziedzictwa kulturowego i dałoby się rzec, tworzą relewantny kontekst w procesie badania poszczególnych literatur. Do takich tekstów w przypadku literatury czeskiej należy bez wątpienia „Moudrost starých Čechü“ autorstwa Romana Jakobsona.

Podstawą owej publikacji, która ukazała się w roku 1943 w ograniczonym nakładzie w Nowym Jorku, były wykłady wygłoszone zimą 1942 roku przez wybitnego naukowca, jednego z twórców fonologii, członka Praskiego Koła Lingwistycznego Romana Jakobsona, który od roku 1939 przebywał na emigracji najpierw w Skandynawii, a później w Stanach Zjednoczonych. „Moudrost starých Čechů“ była trudno dostępna i nikt nie zadbał o jej reedycję, pomimo wysiłków czynionych przez samego autora. Nie ulega wątpliwości, że praca ta zajmuje wyjątkowe miejsce w naukowej spuściźnie Romana Jakobsona. Praktycznie wszystkie prace Jakobsona doczekały się szczegółowych, opatrzonych komentarzami, krytycznych wydań, jedynie „Moudrost starých Čechů“ była pomijana, prawdopodobnie również ze względu na polityczny, antyniemiecki charakter publikacji. Sam Jakobson w latach 1945-1948 pracował wprawdzie nad nowym wydaniem „Moudrosti starých Čechü“, niemniej jednak wydanie nie doszło do skutku. W powojennej Czechosłowacji prawa do wydania tej publikacji otrzymało od Jakobsona wydawnictwo „Čin“, nie dostało ono 
jednak nowej, poprawionej i odpowiednio opracowanej wersji, ale miało do dyspozycji jedynie maszynopis wydania z roku 1943, stanowiący podstawę pierwszego, amerykańskiego wydania dzieła. Fragmenty zostały wprawdzie opublikowane w czechosłowackich czasopismach „Kvart““ i ,Listy“, jednakże bez wiedzy Jakobsona oraz bez uwzględnienia poprawek i uzupełnień, nad którymi Jakobson, wciąż przebywając na emigracji, intensywnie pracował. Po roku 1948 przestały istnieć realne szanse na publikację „,Moudrosti starých Čechü“ w Czechosłowacji, a sam Roman Jakobson nie dokończył projektu nowego wydania dzieła w Stanach Zjednoczonych. Główne założenia dzieła, kontekst, w którym powstało, a także jego ogólne zarysy były powszechnie znane, niemniej jednak sam tekst nie był ogólnie dostępny i stał się swego rodzaju legendą, pomimo iż chodzi przecież o jedną z najobszerniejszych prac Jakobsona poświęconą zagadnieniom bohemistyki - czeskiej kultury, literatury i historii. O wyjątkowości tej publikacji świadczy chociażby fakt, że po amerykańskim wydaniu książki w środowisku czechosłowackiej emigracji rozgorzała gorąca dyskusja na temat pracy Jakobsona. Dyskusja ta również znana była czeskiemu odbiorcy jedynie pośrednio. Dlatego już sam pomysł slawisty Miloša Zelenki i historyka Tomáša Hermanna, by ponownie sięgnąć po „Moudrost starých Čechů“ i wydać tę pracę wraz ze szczegółowym komentarzem i dyskusją, która wybuchła na emigracji, uznać należy za istotny i potrzebny.

Podstawą wydania przygotowanego przez Hermanna i Zelenkę jest oryginalny tekst Jakobsona, który ukazał się w Stanach Zjednoczonych w 1943 roku. Celem natomiast było wypełnienie jednej z białych plam w dziejach czeskiej literatury i naszkicowanie całego skomplikowanego i trudnego do odtworzenia kontekstu powstania pracy Jakobsona, zarysowanie szerokiego spektrum dyskusji, która miała miejsce w środowisku czechosłowackich emigrantów, a także wprowadzenie pracy Jakobsona w nurt szerszej dyskusji o tzw. czeskiej kwestii i debaty o sensie czeskich dziejów.

Publikacja podzielona jest na trzy komplementarne części. Pierwszą stanowi zbudowany z sześciu podrozdziałów szczegółowy, liczący ponad sto stron krytyczny komentarz autorstwa Hermanna i Zelenki zatytułowany „Válečný spis Romana Jakobsona. Mezi strukturální lingvistikou, slavistikou a politizující ideologiî“. Pierwszy podrozdział poświęcony został działalności naukowej Romana Jakobsona w międzywojennej Czechosłowacji. Autorom udało się szczegółowo odtworzyć skomplikowaną intelektualną biografię wybitnego strukturalisty, przytaczając mniej znane fakty z życia Jakobsona, na przykład jego intelektualną współpracę nie tylko z lewicową czeską awangardą, ale także z Jaroslavem Durychem czy słowackimi twórcami (s. 32). Najważniejsze z punktu widzenia czeskiej historii literatury są dwa kolejne rozdziały: drugi poświęcony wyjazdowi na emigrację i powstaniu „Moudrosti starých Čechů“ i trzeci będący szczegółową analizą pracy Jakobsona z różnych punktów widzenia - historycznego, slawistycznego i politycznego. Czwarty podrozdział tworzy komentarz dotyczący debaty w środowisku czechosłowackiej emigracji. Przedostatnia część przynosi interesujące informacje o powojennych losach Jakobsona i o tym, jak jego postać i cały dorobek intelektualny były oceniane w komunistycznej Czechosłowacji. Podsumowaniem obszernego komentarza jest ostatni, szósty podrozdział, rekapitulujący dotychczasową analizę i formujący wnioski.

Kolejna część publikacji to sam tekst Jakobsona, uzupełniony licznymi komentarzami, merytorycznymi przypisami i odnośnikami autorstwa Hermanna i Zelenki. Warto podkreślić, że pierwotne wydanie z 1943 roku nie zawiera żadnych odnośników i żadnych źródeł. W ostatniej części autorzy przypominają najważniejsze głosy dyskusji, która rozgorzała po publikacji „Moudrosti starých Čechů“ w amerykańskich i angielskich czasopismach. Znajdują się tu m. in. teksty Stanislava Budína, Otakara Odložilika czy Jiřího Voskovca. Zelenka i Hermann zdecydowali się również dołączyć do publikacji dodatki: prze- 
mowę Romana Jakobsona wygłoszoną z okazji otrzymania honorowego doktoratu brnieńskiego uniwersytetu im. J. E. Purkyniego w roku 1968, szczegółowe noty biograficzne poszczególnych uczestników dyskusji po publikacji „Moudrosti starých Čechů“, edytorski komentarz, szczegółową listę źródeł, z których korzystali przy tworzeniu publikacji, dodatek graficzny zawierający m. in. mniej znane zdjęcia przedstawiające Roman Jakobsona, rosyjsko i angielskojęzyczne resume oraz indeks nazwisk.

Zestawienie krytycznego wydania „Moudrosti starých Čechů“ po ponad 70 latach od momentu powstania wydaje się być niezwykle potrzebne. Zelenka i Hermann postawili sobie ambitny cel: napisać naukową monografię tego dotychczas trudnodostępnego dla czeskiego czytelnika tekstu Romana Jakobsona. Publikacja przybliża czytelnikowi okoliczności powstania tego chyba najbardziej kontrowersyjnego i najobszerniejszego dzieła Jakobsona dotyczącego bohemistyki, ale jednocześnie na podstawie badania materiałów źródłowych oferuje wgląd w ciekawą recepcję tego dzieła, rekonstruuje najważniejsze elementy debaty w środowisku czechosłowackich intelektualistów żyjących na emigracji. Szczególnie istotna wydaje się być także sama analiza (z różnych punktów widzenia) tego jakże trudnego tekstu, stojącego na granicy między nauką a ideologią, przesyconego ideami czechosłowackiego patriotyzmu. Hermann i Zelenka identyfikowali i definiowali kilka tematów, którym kolejno poświęcali uwagę. Są to: kwestia czechosłowackiego patriotyzmu, który jest niezwykle wyraźny w pracy Jakobsona a jest swego rodzaju echem i intensyfikacją prac wcześniejszych, strukturalistyczne podejście w badaniach naukowych a ,funkcja ideologiczna“, która staje się wyraźnie widoczna właśnie w antyniemieckiej wymowie „Moudrosti starých Čechů“", dyskusja o sensie czeskich dziejów, szczególnie istotna w kontekście sporów przebiegających na emigracji na zachodzie Europy i w Stanach Zjednoczonych.

Zelenka i Hermann są w pełni świadomi tego, że dzieło Jakobsona nie było zawieszone w próżni i nie da się w pełni pokazać wszystkich jego aspektów bez zanurzenia się w kontekst trudnych czasów emigracyjnych. „Moudrost starých Čechů“ to tekst wyjątkowy w całej twórczości Jakobsona, tekst politycznie zaangażowany, eseistyczny, trzeba więc było przyjąć wyjątkową, szeroką perspektywę, dobrać odpowiednie narzędzia i wynaleźć formułę do badania tego specyficznego tekstu. Wydaje się, że Zelence i Hermannowi udało się sprostać temu zadaniu. Nie dali się zwieść emocjonalnemu tonowi Jakobsona, jego głębokiemu czechosłowackiemu patriotyzmowi, udało im się również zachować krytyczny dystans i odpowiednio szeroką perspektywę. Potrafili naszkicować miejsce Jakobsona w międzywojennym życiu intelektualnym Czechosłowacji, ale także jego wpływ na czechosłowacką emigrację w trudnych wojennych i powojennych latach. Na szczególną uwagę zasługuje także zagłębienie się w spory emigracyjne i szczegółowa, obiektywna analiza obu biegunów reakcji na „Moudrost starých Čechů“. Dodatkowo na podkreślenie zasługuje wyjątkowo staranne opracowanie publikacji, także ze strony graficznej.

Nowe wydanie „Moudrosti starých Čechů“ stanowi bez wątpienia ważny krok w naukowym badaniu spuścizny owego „rosyjskiego Czechosłowaka pochodzenia żydowskiego“ (s. 40), jednej z najważniejszych osobowości światowego życia intelektualnego minionego wieku. Zelenka i Hermann odkrywają bowiem mniej znane oblicze strukturalisty i lingwisty Jakobsona, pokazując, że nie mógł on obojętnie przejść obok tragedii II wojny światowej i dał się poznać także jako ideolog, obrońca słowiańskości i utalentowany publicysta. Dzięki publikacji Zelenki i Hermanna widzimy Jakobsona innymi oczami, nie tylko jako wybitnego naukowca, ale także jako autora jednej z najważniejszych polemik z faszystowską ideologią i pseudonauką, które nie doceniały Słowian uznając ich kulturę za wtórną i zależną od innych. 